\title{
Differential Effects of Antipsychotic and Glutamatergic Agents on the phMRI Response to Phencyclidine
}

\author{
Alessandro Gozzi*,', Charles H Large ${ }^{2}$, Adam Schwarz', Simone Bertani ${ }^{2}$, Valerio Crestan ${ }^{2}$ \\ and Angelo Bifone' \\ 'Department of Biology, Psychiatry CEDD, GlaxoSmithKline Medicines Research Centre, Verona, Italy; ${ }^{2}$ Laboratory Animal Science, Psychiatry \\ CEDD, GlaxoSmithKline Medicines Research Centre, Verona, Italy
}

\begin{abstract}
Acute administration of NMDA receptor (NMDAR) antagonists such as phencyclidine (PCP) or ketamine induces symptoms that closely resemble those of schizophrenia in humans, a finding that has led to the hypothesis that a decreased NMDAR function may be a predisposing or even causative factor in schizophrenia. However, the precise neuropharmacological mechanisms underlying these effects remain to be fully elucidated. Here, we applied pharmacological MRI (phMRI) to examine the brain circuitry underlying the psychotomimetic action of PCP in the anesthetized rat, and investigated how these functional changes are modulated by drugs that possess distinct pharmacological mechanisms. Acute administration of PCP $(0.5 \mathrm{mg} / \mathrm{kg}$ i.v. $)$ produced robust and sustained positive relative cerebral blood volume ( $\mathrm{rCBV}$ ) changes in discrete cortico-limbo-thalamic regions. Pretreatment with the selective $\mathrm{D}_{2}$ dopamine antagonist raclopride $(0.3 \mathrm{mg} / \mathrm{kg}$ i.p.) did not significantly affect the rCBV response to PCP, while the atypical antipsychotic clozapine $(5 \mathrm{mg} / \mathrm{kg}$ i.p.) produced region-dependent effects, with complete suppression of the rCBV response in the thalamus, and weaker attenuation of the response in cortical and hippocampal structures. The response to PCP was strongly suppressed in all regions by pretreatment with two drugs that can inhibit aberrant glutamatergic activity: the anticonvulsant lamotrigine $(10 \mathrm{mg} / \mathrm{kg}$ i.p.) and the mGluR2/3 agonist LY354740 (1 0 mg/kg i.p.). Taken together, our findings corroborate the pivotal role of dysfunctional glutamatergic neurotransmission in the functional response elicited by PCP, while the lack of effect of raclopride argues against a primary role of dopamine $D_{2}$ receptor activation in this process. Finally, the thalamic effect of clozapine could be key to elucidating the functional basis of its pharmacological action.

Neuropsychopharmacology (2008) 33, I690- 1703; doi: I 0. I038/sj.npp. I 30 I547; published online 5 September 2007
\end{abstract}

Keywords: fMRI; phencyclidine; clozapine; raclopride; lamotrigine; LY363740

\section{INTRODUCTION}

NMDA receptor (NMDAR) antagonists such as ketamine and phencyclidine (PCP) induce perceptual abnormalities, psychotic symptoms, and mood changes in healthy humans (Adler et al, 1999; Javitt and Zukin, 1991). Many of the symptoms induced by NMDR antagonists are considered similar to those of schizophrenia, and include core symptoms, such as thought disorder and hallucinations (Malhotra et al, 1996). These compounds have also been shown to exacerbate positive symptoms of patients with schizophrenia (Lahti et al, 2001; Malhotra et al, 1997b). Moreover, both clinical and experimental evidence suggest that the expression and functionality of NMDAR might be dysregulated in schizophrenia (Kristiansen et al, 2007; Millan, 2005). These findings have led to the hypothesis that

*Correspondence: A Gozzi, Neuroimaging, Psychiatry CEDD, GlaxoSmithKline Research Centre, Fleming 4, Verona 37100, Italy,

Tel: + 39 0458219233, Fax: + 39 0458218073,

E-mail: alessandro.2.gozzi@gsk.com

Received II May 2007; revised I 8 July 2007; accepted 23 July 2007 a decreased NMDAR function may be a predisposing or even causative factor for this disabling disease (Farber, 2003; Greene, 2001). The similarity between NMDAR antagonist-induced psychosis and schizophrenia has also been widely exploited preclinically to provide models to aid the development of novel treatments for the disorder. In these studies, the ability of drugs to inhibit behaviors induced by NMDAR antagonists is assessed in an attempt to predict the efficacy of novel pharmacological treatments for schizophrenia (reviewed by Large, 2007). Therefore, the site and mode of action of NMDAR antagonists in relation to different symptoms or behaviors that they induce is the object of extensive research.

Neuroimaging studies have provided some initial insights into the site of action of NMDAR antagonists in the human brain. Langsjo et al (2003) reported robust dose-dependent $\mathrm{rCBF}$ increases in the anterior cingulate, thalamus, putamen, and frontal cortex in healthy volunteers receiving ketamine. Consistent findings were observed by McKie et al (2007) using BOLD fMRI. Holcomb et al (2005) showed that ketamine increased cerebral blood flow (CBF) in the anterior cingulate and frontal cortices in both healthy 
volunteers and patients with schizophrenia. Earlier studies also reported that low doses of ketamine affect selectively the areas that are thought to be dysfunctional in schizophrenia such as the limbic cortex and basal ganglia (Morris et al, 2005; Soyka et al, 2005; Tamminga et al, 2003). Recent neuroimaging studies have also examined the regional effects of NMDAR antagonists in the rat. Ketamine has been shown to increase the BOLD response in the hippocampus, retrosplenial cortex, and orbital cortex of anesthetized rats; weaker effects were reported in the nucleus accumbens and ventral pallidum (Littlewood et al, 2006a). Risterucci et al (2005) examined the effects of PCP in the rat using perfusion imaging. They reported increased perfusion in the enthorhinal cortex, nucleus accumbens, thalamus, and ventral pallidum, but decreased perfusion in prefrontal and temporal cortices and dorsal striatum.

Overall, the two studies in rat suggest similarities in the regions of the brain activated by PCP and ketamine, and similarities with respect to regions activated by ketamine in humans. However, no attempt has yet been made to determine the contribution of specific receptor systems to the different regional effects observed in functional studies of NMDAR antagonists. In order to begin to address this question, here we have applied pharmacological MRI (phMRI) methods to investigate the spatio-temporal distribution of relative cerebral blood volume (rCBV) changes induced by acute PCP challenge in the rat, and examined how these changes are modulated by drugs that possess distinct pharmacological mechanisms. As the effect of NMDAR antagonists is thought to involve a dysregulation of glutamatergic neurotransmission (Farber, 2003), we assessed the effect of two drugs that have been suggested to prevent aberrant glutamatergic activity through distinct pharmacological mechanisms: the metabotropic glutamate 2/3 (mGluR2/3) receptor agonist LY354740 and the brain sodium channel blocker lamotrigine. LY354740 has been shown to prevent PCP-induced glutamate release (Moghaddam and Adams, 1998), and to block dose-dependently the behavioral effects of NMDAR antagonists in rodents (Schoepp and Marek, 2002) and in human volunteers (Krystal et al, 2005). Lamotrigine (lamictal, Messenheimer, 1995) is a broad-spectrum anticonvulsant that reduces neuronal excitability and glutamatergic transmission (Large et al, 2005), and that has been shown to prevent psychotic symptoms and disruption of behavior induced by ketamine or PCP in rodents and human volunteers (Idris et al, 2005; Brody et al, 2003; Anand et al, 2000). Moreover, since NMDAR antagonists may be used in preclinical studies to predict the efficacy of novel antipsychotic drugs, we examined the modulation of PCP response by compounds representative of conventional and atypical antipsychotics. Raclopride, a potent and selective dopamine $\mathrm{D}_{2}$ receptor antagonist (Lahti et al, 1993; Kohler et al, 1985), was used to probe the classic mechanism of action of first-generation antipsychotics relying on $\mathrm{D}_{2}$ dopamine blockade. The contribution of dopamine to the psychotogenic action of PCP is still the subject of debate, with the literature showing inconsistent effects of dopamine $\mathrm{D}_{2}$ blockers in rodents (Idris et al, 2005; Linn et al, 2003; Duncan et al, 1998a; Corbett et al, 1995) and humans (Krystal et al, 1999), despite evidence of altered dopamine release following NMDAR antagonist administration (Adams and Moghaddam,
1998). The effect of raclopride was compared with that of clozapine, a prototypical new-generation antipsychotic that, in addition to blocking dopamine $\mathrm{D}_{2}$ receptors, possesses multiple antagonistic actions at several other receptors (Meltzer, 1996). Clozapine has been reported to reverse the cognitive and social behavior deficits induced by NMDAR antagonists in rodents (Idris et al, 2005) and humans (Malhotra et al, 1997a). The parallel investigation of drugs representative of the mechanisms of action of typical and atypical antipsychotics is of great interest in light of the wide preclinical use of NMDAR antagonists as a neuropharmacological model to aid the development of novel treatments for schizophrenia. If these drugs also differentially modify regional brain activation, then it may be possible to link regions to behaviors and to identify the neurofunctional basis of the pharmacological action of antipsychotic drugs.

\section{METHODS}

\section{Animal Preparation}

All in vivo studies were conducted in accordance with the Italian laws (DL 116, 1992 Ministero della Sanità, Roma). Animal research protocols were also reviewed and consented to by a local animal care committee, in accordance with the guidelines of the Principles of Laboratory Animal Care (NIH publication 86-23, revised 1985). The studies were performed on male Sprague-Dawley rats (mean \pm SEM, $293 \pm 33$ g, Charles River, Como, Italy). Animals had free access to standard rat chow and tap water and were housed in groups of five in solid bottom cages with sawdust litter. Room temperature $\left(20-22^{\circ} \mathrm{C}\right)$, relative humidity (45-65\%), and dark-light cycles (12 h each, lights on at 0600 hours) were automatically controlled. After arrival, rats were allowed to acclimatize for at least 5 days.

Animal preparation/monitoring and MRI acquisition in each phMRI study were similar to previous studies (Gozzi et al, 2005). Briefly, rats were anesthetized with $3 \%$ halothane in a $30 \%: 70 \% \mathrm{O}_{2}: \mathrm{N}_{2}$ gas mixture, tracheotomized, and artificially ventilated with a mechanical respirator. The left femoral artery and vein were cannulated and animals were paralyzed with a $0.25 \mathrm{mg} / \mathrm{kg}$ i.v. bolus of D-tubocurarine followed by a continuous infusion of $0.25 \mathrm{mg} / \mathrm{kg} / \mathrm{h}$ through the artery. All wounds were infiltrated with $1 \%$ lidocaine before incision. A PE50 cannula was also inserted intraperitoneally for drug pretreatment. After surgery the rat was secured into a customized stereotactic holder (Bruker, Ettlingen, Germany) and the halothane level set to $0.8 \%$. The ventilation parameters were adjusted to maintain physiological arterial blood gases levels according to $\mathrm{p}_{\mathrm{a}} \mathrm{CO}_{2}$ and $\mathrm{p}_{\mathrm{a}} \mathrm{O}_{2}$ measurements performed during the study. A statistical comparison of $\mathrm{p}_{\mathrm{a}} \mathrm{CO}_{2}$ values using ANOVA and a Fisher's LSD test for multiple comparisons did not reveal any significant difference between pre- and post-MRI $\mathrm{p}_{\mathrm{a}} \mathrm{CO}_{2}$ values, or between treatment groups. A magnetic resonance-compatible thermocouple probe was used to measure rectal temperature. The body temperature of all subjects was maintained within physiological range $\left(37 \pm 0.8^{\circ} \mathrm{C}\right)$ throughout the experiment, by using a water heating system incorporated in the stereotactic holder. Mean arterial blood pressure (MABP) was monitored continually through the femoral artery. At the end of the 
experiment, the animals were euthanized with an overdose of anesthetic followed by cervical dislocation.

\section{rCBV Measurement}

MRI data were acquired using a Bruker Avance 4.7 Tesla system, a $72 \mathrm{~mm}$ birdcage resonator for radio frequency pulse transmit and a Bruker curved 'Rat Brain' quadrature receive coil. The MR acquisition for each subject comprised $\mathrm{T}_{2}$-weighted anatomical images using the RARE sequence (Hennig et al, 1986) $\left(\mathrm{TR}_{\text {eff }}=5000 \mathrm{~ms}, \mathrm{TE}_{\text {eff }}=76 \mathrm{~ms}\right.$, RARE factor 8 , FOV $40 \mathrm{~mm}, 256 \times 256$ matrix, 16 contiguous $1 \mathrm{~mm}$ slices) followed by a time series acquisition with the same spatial coverage and similar parameters $\left(\mathrm{TR}_{\mathrm{eff}}=2700 \mathrm{~ms}\right.$, $\mathrm{TE}_{\text {eff }}=110 \mathrm{~ms}$, RARE factor 32), but with a lower in-plane spatial resolution $(128 \times 128)$ giving a functional pixel volume of $\sim 0.1 \mathrm{~mm}^{3}$. The use of $\mathrm{T}_{2}$-weighted images for the time-series acquisition minimizes sensitivity to both large blood vessels and inhomogeneities of the static magnetic field (Boxerman et al, 1995), and also ensured that the geometry of the time-series images matched the anatomical reference images, facilitating subsequent image analysis. Two successive scans were averaged for a resulting time resolution of $40 \mathrm{~s}$. Following five reference images, $2.67 \mathrm{ml} /$ $\mathrm{kg}$ of the blood pool contrast agent Endorem (Guerbet, France) was injected so that subsequent signal changes would reflect alterations in relative $\mathrm{rCBV}$ (Mandeville et al, 1998). Prior to the injection of drug pretreatment, an equilibration period of $15 \mathrm{~min}$ was allowed. Experiments (see below) were performed following an antagonist-agonist design, with intraperitoneal injection of drug (or vehicle) pretreatment followed by PCP challenge (or vehicle) $30 \mathrm{~min}$ later. The MRI data were acquired over a period of at least 20 min following the administration of the PCP challenge.

\section{Experiments and Compounds}

Rats were randomly assigned to one of the following treatment groups:

(1) Intraperitoneal preadministration of vehicle (water, $1 \mathrm{ml} / \mathrm{kg}$ ) followed by an intravenous challenge with PCP (phencyclidine hydrochloride, Sigma-Aldrich, Italy, $0.5 \mathrm{mg} / \mathrm{kg}, 1 \mathrm{ml} / \mathrm{rat}) 30 \mathrm{~min}$ later $(n=24)$;

(2) Intraperitoneal preadministration of raclopride $(S(-)$ raclopride (+ )-tartrate, Sigma-Aldrich, Italy, $0.3 \mathrm{mg} / \mathrm{kg})$ followed by an intravenous challenge with PCP $(0.5 \mathrm{mg} /$ $\mathrm{kg}) 30$ min later $(n=6)$;

(3) Intraperitoneal preadministration of clozapine (SigmaAldrich, Italy, $5 \mathrm{mg} / \mathrm{kg}$ ) followed by an intravenous challenge with PCP $(0.5 \mathrm{mg} / \mathrm{kg}) 30$ min later $(n=7)$;

(4) Intraperitoneal preadministration of LY354740 (GSK, Italy, $10 \mathrm{mg} / \mathrm{kg}$ ) followed by an intravenous challenge with PCP $(0.5 \mathrm{mg} / \mathrm{kg}) 30 \mathrm{~min}$ later $(n=7)$;

(5) Intraperitoneal preadministration of lamotrigine (lamictal, lamotrigine isothionate, GSK, Italy, $10 \mathrm{mg} / \mathrm{kg}$ free base) followed by an intravenous challenge with PCP $(0.5 \mathrm{mg} / \mathrm{kg}) 30 \mathrm{~min}$ later $(n=6)$;

(6) Intraperitoneal preadministration of vehicle (water) followed by an intravenous challenge with vehicle (saline, $1 \mathrm{ml} / \mathrm{rat}$ ) $30 \mathrm{~min}$ later $(n=6)$. This group of rats was used as double-negative control group (baseline).
All the compounds were injected at a rate of $1 \mathrm{ml} / \mathrm{min}$. PCP was dissolved in saline, while all the pretreatments were dissolved in water. Clozapine was dissolved in a few drops of $1 \mathrm{~N} \mathrm{HC1}$ and brought to volume with water. The final $\mathrm{pH}$ of the clozapine solution was adjusted to 7 with a few microliters of $1 \mathrm{~N} \mathrm{NaOH}$. The doses chosen for the different drugs were based on previously published in vivo studies. PCP at $0.5 \mathrm{mg} /$ $\mathrm{kg}$ i.v. has been shown to elicit robust behavioral and metabolic (2DG) effects in freely moving rats (Weissman et al, 1987). The dose of raclopride used in this study $(0.3 \mathrm{mg} / \mathrm{kg}$ i.p.) produces $\sim 75 \%$ dopamine $\mathrm{D}_{2}$ receptor occupancy, a value that ensures a robust antipsychotic response without inducing cataleptic behavior (Wadenberg et al, 2000). The dose of clozapine tested $(5 \mathrm{mg} / \mathrm{kg}$ i.p.) has been shown to produce a $\mathrm{D}_{2}$ receptor occupancy of approximately $40 \%$ (see Kapur et al, 2003; Schotte et al, 1993, 1996), with one study showing a slightly lower value (ca. 25\%, Mukherjee et al, 2001). These values are consistent with those determined in schizophrenic patients treated with clozapine (eg 16-68\% in Kapur et al, 1999; 20-67\% in Nordstrom et al, 1995). The same dose of clozapine ensures serotonin $5-\mathrm{HT}_{2 \mathrm{~A}}$ receptor occupancy analogous to the one measured in the clinical condition (ca. 80 vs 84-94\%, Nordstrom et al, 1995; Schotte et al, 1995). Clozapine at $5 \mathrm{mg} / \mathrm{kg}$ i.p. has also been shown to prevent the behavioral and metabolic effects of PCP and other NMDAR antagonists in freely moving rats (Idris et al, 2005; Duncan et al, 1998a, 2000; Corbett et al, 1995; Bakshi et al, 1994). Therefore, the dose selected produces robust pharmacological effects while maintaining its 'atypicality' with regard to the degree of $\mathrm{D}_{2}$ receptor occupancy, a feature that differentiates this clozapine from atypical antipsychotics and most new-generation neuroleptics such as risperidone and olanzapine (Kapur et al, 1999). LY354740 at $10 \mathrm{mg} / \mathrm{kg}$ i.p. has been shown to prevent the behavioral and neurochemical effects of PCP (Schoepp and Marek, 2002). Lamotrigine was given at a nonsedative dose $(10 \mathrm{mg} / \mathrm{kg}$ i.p.), which was recently shown to affect PCP-induced disruption of a reversal learning task in rats (Idris et al, 2005).

\section{Data Analysis}

The rCBV time-series image data for each experiment were analyzed within the framework of the general linear model (GLM). Signal intensity changes in the time series were converted into fractional rCBV on a pixel-wise basis, using a constrained exponential model of the gradual elimination of contrast agent from the blood pool (Schwarz et al, 2003). Individual subjects in each study were spatially normalized by a nine-degree-of-freedom affine transformation mapping their $\mathrm{T}_{2}$-weighted anatomical images to a stereotaxic rat brain MRI template set (Schwarz et al, 2006a) and applying the resulting transformation matrix to the accompanying rCBV time series. RCBV time series for the PCP challenge were calculated covering $8 \mathrm{~min}$ (12 time points) preinjection baseline and $20 \mathrm{~min}$ (30 time points) postinjection window, normalized to a common injection time point. RCBV time series were also calculated for the pretreatment covering $6 \mathrm{~min}$ (9 time points) preinjection baseline and $20 \mathrm{~min}(30$ time points) postinjection window normalized to a common injection time point. Image-based time series analysis was performed using FEAT (FMRI Expert Analysis Tool) Version 5.63, part of FSL (FMRIB's Software Library, 
www.fmrib.ox.ac.uk/fsl) with $0.8 \mathrm{~mm}$ spatial smoothing $(\approx 2.5 \times$ in-plane voxel dimension $)$ and using a model function identified by Wavelet Cluster Analysis (WCA) across all animals in the cohort, capturing the temporal profile of the signal change induced by PCP challenge in each group (Figure 1 inset shows the model function chosen for PCP response in vehicle-PCP group) (Schwarz et al, 2006b; Whitcher et al, 2005). The design matrix also included the temporal derivative of this regressor and a linear ramp (both orthogonalized to the regressor of interest). The coefficients of the model function thus provided a map of rCBV response amplitude for each injection in each subject. Higher level group comparisons were performed using FLAME (FMRIB's Local Analysis of Mixed Effects); $Z$ (Gaussianized T/F) statistic images were thresholded using clusters determined by $Z>2.3$ and a corrected cluster significance threshold of $p=0.01$ (Friston et al, 1994; Worsley et al, 1992). Maps of the attenuation of the PCP response by pretreatments were created comparing the $\mathrm{rCBV}$ response of the vehicle-PCP group (group 1) vs each pretreated group (groups 2-5). Attenuation maps were also thresholded using clusters determined by $Z>2.3$ and a corrected cluster significance threshold $\left(P_{c}\right)$ of $p=0.01$. The anatomical distribution of the $\mathrm{rCBV}$ changes in both the activation and attenuation maps was used as guide for a selection of VOIs, which were used to quantify and compare the efficacy of the pretreatment.
VOI time courses for both the pretreatment and the PCP challenge were extracted from unsmoothed rCBV time series data using a 3D digital reconstruction of a rat brain atlas (Paxinos and Watson, 1998) co-registered with the MRI template (Schwarz et al, 2006a), using custom in-house software written in IDL (Research Systems Inc., Boulder, Colorado). A list with the anatomical definition of the VOIs examined that has been previously described can be found in nucleus accumbens $(A c b)$; caudate putamen $(C p u)$; antero-dorsal region of the hippocampus (regions of hippocampus dorsal to a line $5.5 \mathrm{~mm}$ ventral from bregma, Figures 25-35 in Paxinos and Watson (1998), hippocampus $A D$ ); postero-dorsal region of the hippocampus (regions of hippocampus dorsal to a line $5.5 \mathrm{~mm}$ ventral from bregma, Figures 36-45 in Paxinos and Watson (1998), excluding subiculum and DG region in Figure 45, hippocampus $P D$ ); ventral hippocampus (regions of hippocampus greater than $5.5 \mathrm{~mm}$ ventral from bregma, Figures $36-45$ in Paxinos and Watson (1998), excluding subiculum and DG region in Figure 45, hippocampus V); posterior layers of the dentate gyrus (DG and PoDG regions, Figures 45-47 in Paxinos and Watson (1998), hippocampus PDG); dorso-lateral thalamus (thalamus DL); medio-dorsal thalamus (thalamus $M D$ ); ventro-medial thalamus (thalamus VM); lateral hypothalamus $(L H)$; ventro-lateral part of latero-dorsal thalamus $(L D V L)$; dorso-medial part of latero-dorsal thalamus $(L D D M)$; hypothalamus (Hth); medial prefrontal cortex

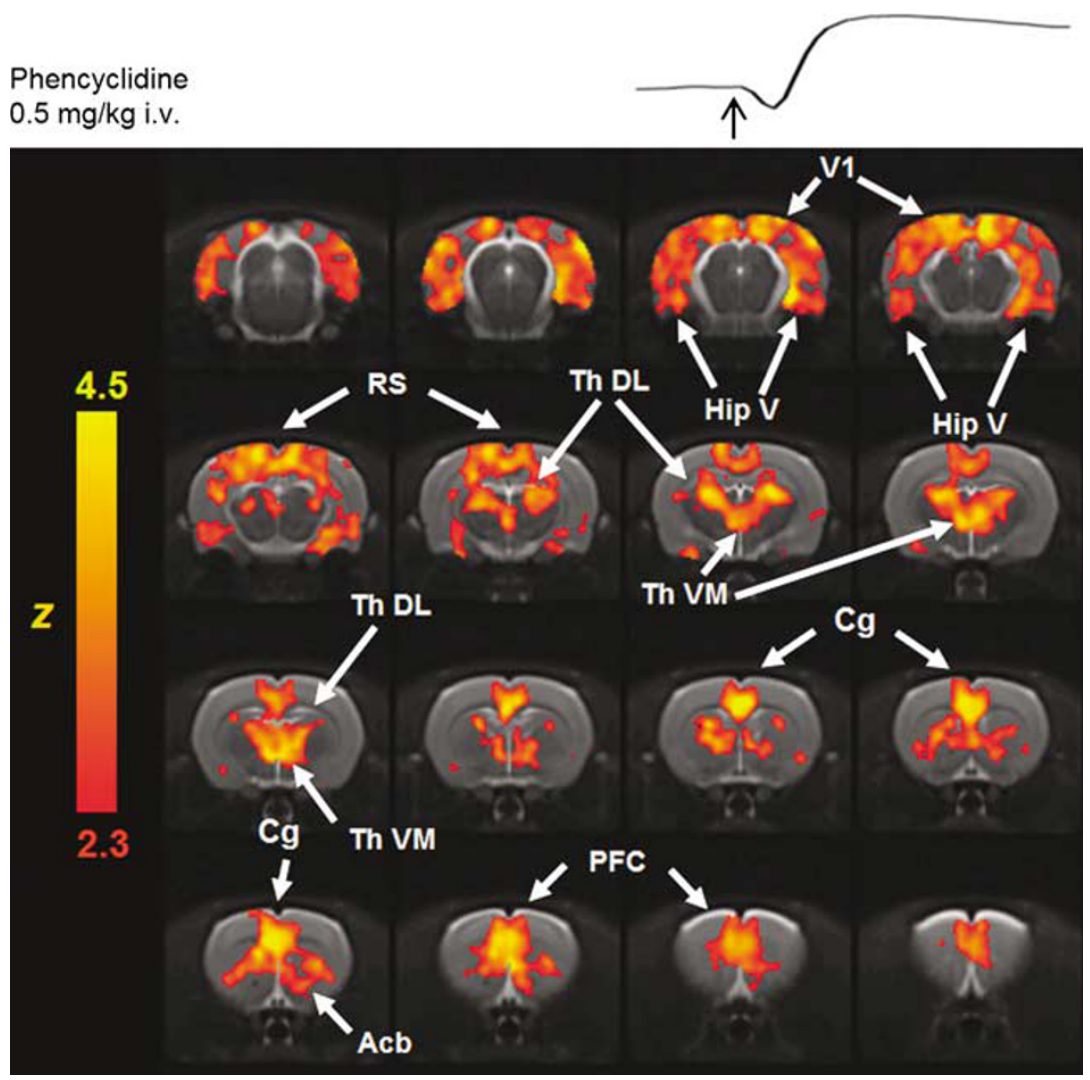

Figure I Maps of rCBV response following acute phencyclidine (PCP) challenge $(0.5 \mathrm{mg} / \mathrm{kg}$ i.v.; $n=24)$ relative to vehicle ( $n=6)$. Orange/yellow indicated increased rCBV vs baseline (vehicle). The temporal profile of the regressor used as a signal model in the general linear model (GLM) analysis (see Methods) is shown at the top right of the activation map, with an arrow indicating the time of injection. (Abbreviations: VI, primary visual cortex; VHip, ventral hippocampus; RS, retrosplenial cortex; DLth, dorso-lateral thalamus; VMth, ventro-medial thalamus; $\mathrm{Cg}$, cingulate cortex, Acb, nucleus accumbens; mPFC, medial prefrontal cortex.) 
$(P F C)$; cingulate cortex $(C g)$; orbito-frontal cortex $(O F C)$; retrosplenial cortex $(R S)$; motor cortex $(M C)$; primary somatosensory cortex (S1); primary visual cortex (V1); entorhinal cortex (includes ectorhinal and perirhinal areas) $(E n t)$; piriform cortex (includes both Pir layer and adjacent tissue, Pir); insular cortex (Ins); parietal association cortex $(P t A)$; temporal association cortex $(\mathrm{TeA})$; ventral tegmental area $(V T A)$; substantia nigra $(S N)$; raphe nuclei (raphe); superior colliculi (SupCo); pons (pons); amygdala (includes basolateral and basomedial and medial amygdaloid nuclei plus central nucleus of the amygdala, Amy).

For each VOI time course, the average rCBV over a $16 \mathrm{~min}$ time window covering the peak response to PCP (4-20 min post injection) was used as a summary statistic of the relative change. The effect of pretreatment on the magnitude of average rCBV in different VOIs was assessed by a one-way ANOVA followed by a Dunnett's test $v s$ group 1. Threshold for statistical significance was considered as $p=0.05$. Results are quoted and displayed as mean \pm SEM unless otherwise indicated.

The rCBV time profiles of the intraperitoneal pretreatment per se did not show clear or sustained signal changes compared to vehicle for all the compounds in any of the VOIs examined (PFC, RS, V1, S1, Pir, Ins, OFC, Ent cortices, LD and VM thalami, Hth, Hc, Cpu, Acb, septum, VTA, SupCo, Amy, SN).

Pretreatment and PCP administration produced transient alterations of MABP whose peak magnitude was well within the $\mathrm{CBF}$ autoregulation range $60-120 \mathrm{~mm} \mathrm{Hg}$ under halothane anesthesia. Experiments performed in our lab using the same anesthetic protocol applied here have shown that pharmacologically evoked MABP changes within the autoregulation range mentioned above do not result in significant central rCBV response (Gozzi et al, 2007a).

\section{RESULTS}

PCP $(0.5 \mathrm{mg} / \mathrm{kg})$ induced a robust activation of distinct cortico-limbo-thalamic structures (Figure 1). Significant positive rCBV changes $(Z>2.3$ vs vehicle, cluster correction at $p=0.05$ ) were observed in limbic cortical regions (medial prefrontal, cingulate, orbito-frontal, and retrosplenial cortices), with extension into the motor, visual, parietal-, and temporal association and rhinal cortices. Significant foci of activation were also observed in specific subcortical structures, including the medial and lateral habenula, amygdala, antero-dorsal, dorso-lateral and ventro-medial thalamus, postero-dorsal, antero-dorsal and ventral and posterior hippocampus, the dorsal striatum, and the nucleus accumbens. The time course of PCP-induced activation was similar in all the activated regions (eg medial prefrontal cortex, hippocampus, and latero-dorsal thalamus, Figure 2), with a brief dip followed by a rapid increase in $\mathrm{rCBV}$ that reached a plateau within $5 \mathrm{~min}$ of drug injection, and remained sustained over the period examined. In nonactivated regions (eg somatosensory cortex, Figure 2), the transient dip was not followed by any appreciable increase in $\mathrm{rCBV}$ with respect to control animals challenged with vehicle (baseline). The magnitude of the rCBV response to PCP was region-dependent, with the largest response in specific subregions of the cortex and the thalamus (eg mean rCBV increase at peak in cingulate $+17.7 \pm 1.7 \%$ and prefrontal cortex $+14.9 \pm 1.6 \%$, respectively; $+19.0 \pm 1.6 \%$ and $+19.3 \pm 2.3 \%$ in ventro-medial and dorso-lateral thalami, respectively). Smaller changes in rCBV were observed in other cortical areas (eg visual cortex $+11.9 \pm 1.2 \%$ ) and subcortical structures (eg ventral hippocampus $+10.0 \pm 1.2 \%$ ). These effects are summarized in Figure 3. PCP did not produce significant changes in rCBV with respect to vehicle in the somatosensory, piriform and insular cortices, hypothalamus, superior colliculi, or cerebellum.

PCP administration produced a rapid rise in MABP $(+8.9 \pm 3.3 \mathrm{~mm} \mathrm{Hg}$, peak $1 \mathrm{~min}$ post injection) followed by an undershoot $(-6.9 \pm 2.1 \mathrm{~mm} \mathrm{Hg})$, which returned to preinjection baseline $(99.2 \pm 3.1 \mathrm{~mm} \mathrm{Hg})$ about $10-12 \mathrm{~min}$ post injection. Intraperitoneal preadministration of vehicle also produced a transient $(\approx 2 \mathrm{~min})$ change in arterial blood pressure $(-30 \mathrm{~mm} \mathrm{Hg})$. The injection of vehicle produced negligible $\mathrm{rCBV}$ changes per se in all the brain regions examined.

\section{Clozapine}

Preadministration of clozapine ( $5 \mathrm{mg} / \mathrm{kg}$ i.p.) significantly inhibited the rCBV response to PCP in the cortex, thalamus, antero-dorsal hippocampus, and striatum (Figure 4). The degree of inhibition varied by region, with foci of strong inhibition in the dorso-lateral and ventro-medial thalami $(p=0.0002$ and 0.001 , respectively), areas of moderate inhibition in the medial prefrontal $(p=0.02)$, cingulate $(p=0.01)$, and visual cortices $(p=0.01)$, and regions of weak and nonsignificant inhibition in the ventral hippocampus and posterior dentate gyrus $(p=0.30$ and 0.18 , respectively). These effects could also be clearly seen in the rCBV time courses (Figures 2 and 4). Cortical regions such as the medial prefrontal cingulate, retrosplenial, temporal association, and visual cortices showed an attenuated, but sustained response to PCP, which lasted throughout the time window examined. In areas of stronger inhibition by clozapine, such as the latero-dorsal and ventro-medial thalami and dorsal striatum, no appreciable $\mathrm{rCBV}$ response to PCP was observed. Total suppression of PCP activation was also observed in strongly responding subthalamic nuclei such as the LDVL and LDDM (dorso-medial and ventro-lateral part of latero-dorsal thalamus, $p=0.0003$ and 0.00008 respectively). A trend for a subregional specificity in clozapine response was also observed in the hippocampus. Clozapine significantly inhibited PCP activation in the antero-dorsal and posterior dorsal hippocampus $(p=0.02$ in both regions). However, clozapine did not significantly inhibit PCP-induced activation of the ventral hippocampus or posterior dentate gyrus. Within the basal ganglia, clozapine significantly inhibited PCP-induced activation in the striatum $(p=0.006)$, but failed to suppress activation in the nucleus accumbens $(p=0.35)$.

Preadministration of clozapine was followed by a gradual decrease in MABP $(-25.6 \pm 8.3 \mathrm{~mm} \mathrm{Hg})$, which plateaued 4-6 min after injection. The effect persisted for more than 30 min and was still present at the time of PCP challenge. The rCBV changes produced by preadministration of clozapine per se were negligible in all the brain regions examined (Figure 5). 

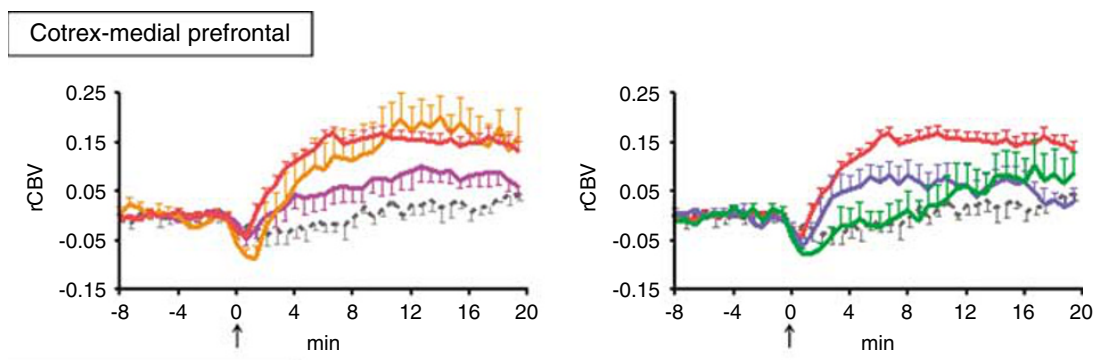

Cortex-somatosensory
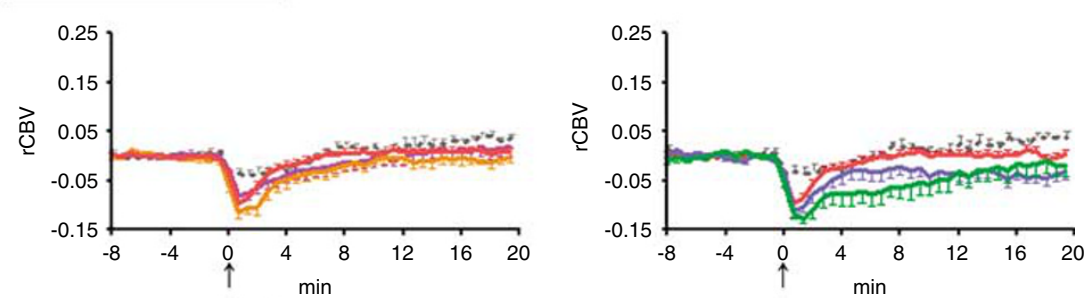

Ventral Hippocampus
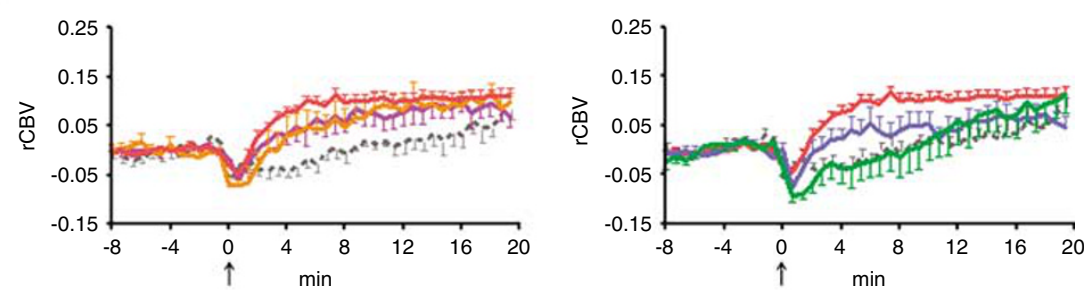

Laterodorsal Thalamus
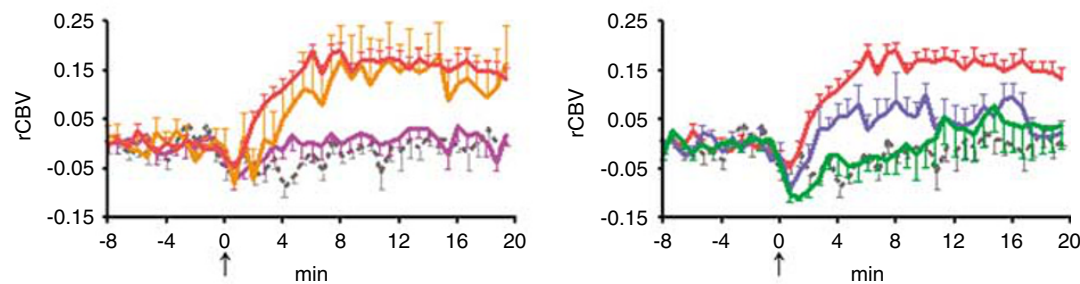

․ Baseline - Vehicle - Clozapine $5 \mathrm{mg} / \mathrm{kg}$ - Raclopride $0.3 \mathrm{mg} / \mathrm{kg}$
— Lamotrigine $10 \mathrm{mg} / \mathrm{kg}$ - LY354740 $10 \mathrm{mg} / \mathrm{kg}$

Figure 2 rCBV time course following phencyclidine (PCP) injection as a function of pretreatment in four representative brain structures. Arrows indicate the time of PCP injection. Baseline data were obtained in animals pretreated and challenged with vehicle (saline). Data are plotted as mean \pm SEM within each group. (clozapine-PCP $n=7$; raclopride-PCP $n=6$; lamotrigine-PCP $n=6$, LY354740-PCP $n=7$; vehicle-PCP $n=24$.)

\section{Raclopride}

Intraperitoneal pretreatment with raclopride $(0.3 \mathrm{mg} / \mathrm{kg})$ did not significantly attenuate the response to PCP in any of the regions examined (Figures 2 and 4). However, a trend toward attenuation was observed in the dorso-lateral thalamus ( $p=0.10$, Figure 4$)$, caudate putamen, and nucleus accumbens ( $p=0.08$ and 0.11 , respectively; Figure 4). Equally, the time course of rCBV changes following PCP administration in raclopride-treated rats was not significantly modified compared to control, in either the regions activated by PCP (eg thalamus, limbic cortex, hippocampus) or those not activated by PCP (eg somatosensory cortex, Figures 2 and 4). Raclopride did not produce significant alterations of basal MABP, with respect to vehicle, and the rCBV changes produced by preadministration of raclopride per se were negligible in all the brain regions examined (Figure 5).

\section{LY354740}

LY354740 (10 mg/kg i.p.) induced a significant inhibition of the rCBV response to PCP in all the activated regions examined (Figures 2 and 4). The inhibition was marked in all activated cortical areas $(p<0.001$ in all regions examined, Figure 4). Marked inhibition was also observed in the ventro-medial thalamus $(p=0.009)$ and dorsal hippocampus $(p=0.002)$. Significant inhibition was observed also in mesolimbic areas such as the striatum and the nucleus accumbens ( $p=0.02$ and 0.04 , respectively). Time course analysis of rCBV changes showed a significant inhibition of the response to PCP in animals pretreated with 


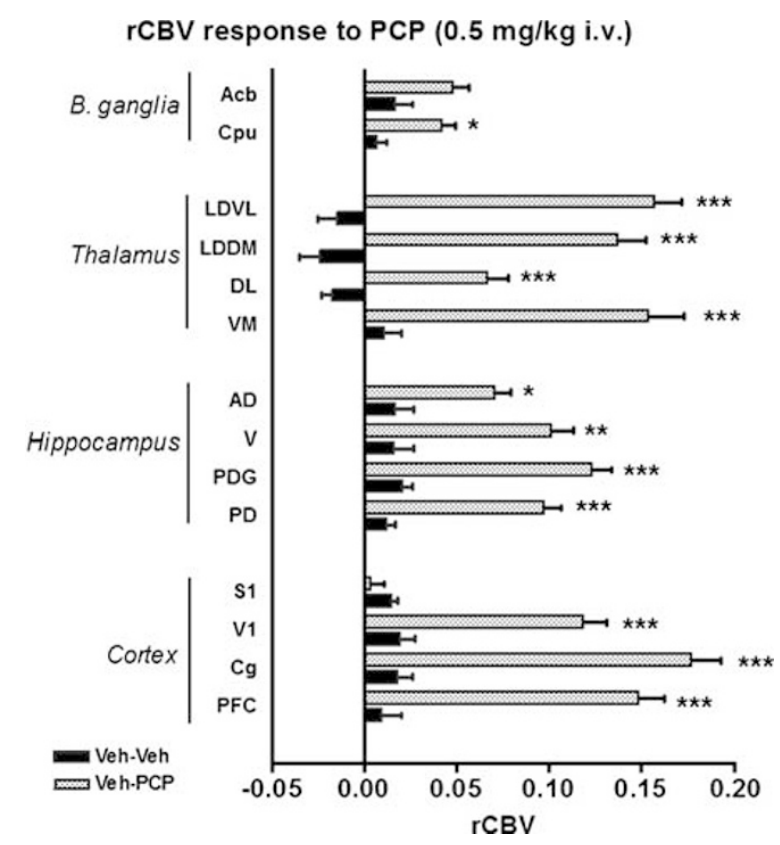

Figure $3 \quad r C B V$ response to PCP in representative VOls. The effect was plotted as mean rCBV over a 16 min time window covering the peak response to phencyclidine (PCP) (4-20 min post injection). Baseline data of control animals pretreated and challenged with vehicle are reported for comparison (vehicle-vehicle). $* p<0.05$, *** $p<0.0$ I, **** $p<0.00$ I, vs vehicle-vehicle. (Abbreviations: Acb, nucleus accumbens; Cpu, caudate putamen; LDVL ventro-lateral part of latero-dorsal thalamus, LDDM dorsomedial part of latero-dorsal thalamus, DL, dorso-lateral thalamus; VM, ventro-medial thalamus, $A D$, antero-dorsal hippocampus; $V$, ventral hippocampus; PDG, posterior dentate gyrus; PD, postero-dorsal hippocampus; SI, primary somatosensory cortex; VI, primary visual cortex; $\mathrm{Cg}$, cingulate cortex; PFC, medial prefrontal cortex.)

LY354740 both in the amplitude and the duration of the response (Figure 2). As observed with lamotrigine, weak but sustained rCBV decreases in cortical areas were observed upon the injection of PCP after LY354740 pretreatment, particularly in the motor and somatosensory regions (eg somatosensory cortex, $p=0.01$, Figures 2 and 4). LY354740 did not produce significant alterations of basal MABP, with respect to vehicle, and the $\mathrm{rCBV}$ changes produced by preadministration of LY354740 per se were negligible in all the brain regions examined (Figure 5).

\section{Lamotrigine}

Lamotrigine $(10 \mathrm{mg} / \mathrm{kg}$ i.p. $)$ significantly inhibited the activation induced by PCP in all regions (Figures 2 and 4). The effect was particularly marked in strongly responding cortical regions, such as prefrontal, cingulate, and retrosplenial cortices, where preadministration of lamotrigine completely suppressed the PCP response $(p=0.002$, 0.0003 , and 0.002 , respectively). Robust or complete suppression was also observed in key subcortical structures including the ventro-medial and dorso-lateral thalamus $(p=0.004$ and 0.003 , respectively), the hippocampus $(p<0.02$ in all the hippocampal regions examined), and the dorsal striatum $(p=0.006)$. Time course analysis of rCBV changes showed robust inhibition of the response to PCP over the period examined (Figure 2). Weak but sustained rCBV decreases in cortical areas were observed upon the injection of PCP after lamotrigine pretreatment, particularly in the motor and somatosensory regions (eg somatosensory cortex, $p=0.005$, Figures 2 and 4).

The administration of lamotrigine did not produce significant alterations of basal MABP with respect to vehicle, and the $\mathrm{rCBV}$ changes produced by preadministration of lamotrigine per se were negligible in all the brain regions examined (Figure 5).

\section{DISCUSSION}

Acute administration of NMDAR antagonists like phencyclidine (PCP) or ketamine induces symptoms that closely resemble those of schizophrenia in humans, a finding that led to the hypothesis that a decreased NMDAR function may be a predisposing or even causative factor in schizophrenia. However, the brain circuitry and the precise neuropharmacological mechanisms underlying these effects remain to be fully elucidated. Here, we applied phMRI to examine the brain circuitry underlying the psychotomimetic action of PCP, and investigated how these functional changes are modulated by drugs that possess distinct pharmacological mechanisms. Acute administration of PCP produced robust activation of cortico-limbo-thalamic regions. Pretreatment with the selective $\mathrm{D}_{2}$ dopamine antagonist raclopride did not significantly affect the rCBV response to $\mathrm{PCP}$, while the atypical antipsychotic clozapine produced region-dependent effects, with complete suppression of the rCBV response in the thalamus, and weaker attenuation of the response in cortical and hippocampal structures. The response to PCP was also strongly suppressed by pretreatment with two drugs that can prevent aberrant glutamatergic activity: the anticonvulsant lamotrigine and the mGluR2/3 agonist LY354740.

\section{rCBV Response to PCP}

Acute administration of PCP produced a robust and reproducible increase in $\mathrm{rCBV}$ in discrete cortico-limbic, thalamic, and hippocampal regions. Multiple lines of evidence argue that the rCBV changes observed reflect underlying neuronal activation. First, the observed rCBV increases are unlikely to be the result of global hemodynamic effects, since PCP induced a sustained activation of discrete cortical and subcortical structures, with no effects in other regions. Next, PCP and the intraperitoneal pretreatments induced only modest and transient alterations of arterial blood pressure. The magnitude of these changes under halothane anesthesia was well within the range $(60-120 \mathrm{~mm} \mathrm{Hg})$ within which abrupt pharmacological manipulation of MABP can be homeostatically compensated without producing significant alterations of $\mathrm{CBV}$ (Gozzi et al, 2007a). Finally, the observed pattern of rCBV changes is consistent with the results from studies of the functional effects of NMDAR antagonists performed with a variety of other measures in ex vivo experiments that should not be sensitive to hemodynamic confounds; eg ${ }^{14} \mathrm{C}-2$ deoxyglucose (2DG) uptake and immediate early gene expression (Duncan et al, 1999c, d; Nakki et al, 1996).

The use of anesthetic is a putative confound that can potentially affect the sign and distribution of the functional response. This aspect has been extensively studied in our 
Effect of pretreatment on rCBV response to PCP
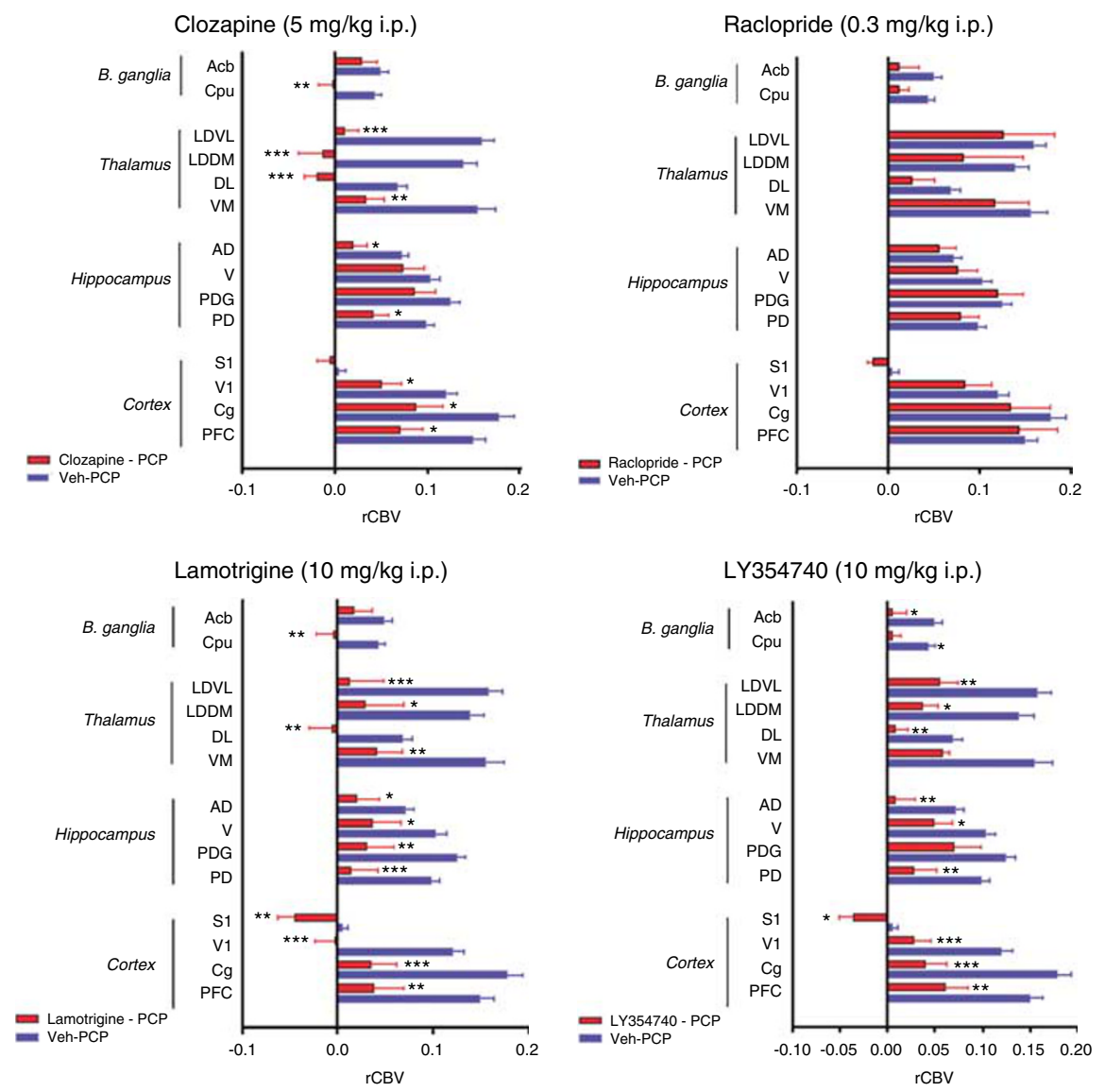

Figure 4 Effect of pretreatment on the rCBV response to phencyclidine $(P C P)$ in representative VOls. Data are expressed as mean \pm SEM (clozapinePCP $n=7$; raclopride-PCP $n=6$; lamotrigine-PCP $n=6$; LY354740-PCP $n=7$; vehicle-PCP $n=24)$. $* p<0.05$, *** $p<0.0$ I, **** $p<0.00$ I, vs vehicle-PCP. (Abbreviations: Acb, nucleus accumbens; Cpu, caudate putamen; LDVL, ventro-lateral part of latero-dorsal thalamus; LDDM, dorso-medial part of laterodorsal thalamus; $\mathrm{DL}$, dorso-lateral thalamus; $\mathrm{VM}$, ventro-medial thalamus; $\mathrm{AD}$, antero-dorsal hippocampus; $\mathrm{V}$, ventral hippocampus; PDG, posterior dentate gyrus; PD, postero-dorsal hippocampus; SI, primary somatosensory cortex; VI, primary visual cortex; Cg, cingulate cortex; PFC, medial prefrontal cortex.)

lab through a comprehensive series of studies aimed to identify a dose of PCP and an anesthetic level that resulted in a pattern of activation consistent with the result of neurofunctional studies performed in conscious animals (eg single unit recording, $\left[{ }^{14} \mathrm{C}\right]$-iodoantipyrine CBF measurements, 2-deoxyglucose uptake etc). This work has highlighted a critical interaction between PCP and maintenance anesthetic, with the appearance of widespread brain deactivation as the level of anesthesia or PCP dose is increased. However, when rats were imaged under $0.8 \%$ halothane anesthesia and challenged with a subanesthetic dose of PCP $(0.5 \mathrm{mg} / \mathrm{kg}$ i.v. $)$, robust and reproducible activation of discrete cortico-limbo-thalamic structures was observed (Gozzi et al, 2007b). These conditions were, therefore, used in the present study. Several lines of evidence support the suggestion that the observed pattern of activation is representative of the central effects of PCP in freely moving animals and in humans. First, the observation of activation in response to PCP is consistent with the excitatory effects of NMDAR antagonists observed in freely moving rodents, measured with single unit recording (Homayoun et al, 2005), $\left[{ }^{14} \mathrm{C}\right]$-iodoantipyrine CBF measurements (Cavazzuti et al, 1987), and 2DG (Miyamoto et al, 2000; Duncan et al, 1998a, b, 1999b, 2000; Weissman et al,
1987; Meibach et al, 1979). Second, the anatomical distribution of $\mathrm{rCBV}$ changes is consistent with regions of increased 2DG uptake in conscious rats upon injection of NMDAr antagonist such as PCP, ketamine, or MK-801 (Duncan et al, 1999a). Third, the pattern of functional changes described in the present work is very similar to that observed in neuroimaging studies of the effects of ketamine in healthy humans. For example, Langsjo et al (2003) reported robust dose-dependent $\mathrm{rCBF}$ increases in the anterior cingulate, thalamus, putamen, and frontal cortex in healthy human volunteers receiving ketamine. McKie et al (2007) using BOLD fMRI also report a similar pattern in healthy human volunteers. Taken together, these observations suggest that the level of anesthesia (and dose of PCP) used in the present study did not qualitatively affect the central effects of PCP.

Other groups have also examined the regional effects of NMDAR antagonists in the rat brain using neuroimaging techniques. Subanesthetic doses of ketamine in isofluraneanesthetized rats were shown to increase the BOLD response in the hippocampus, the retrosplenial and orbital cortices, the nucleus accumbens, and the ventral pallidum (Littlewood et al, 2006a,b), regions that have also been identified in the present study. Risterucci et al (2005) 

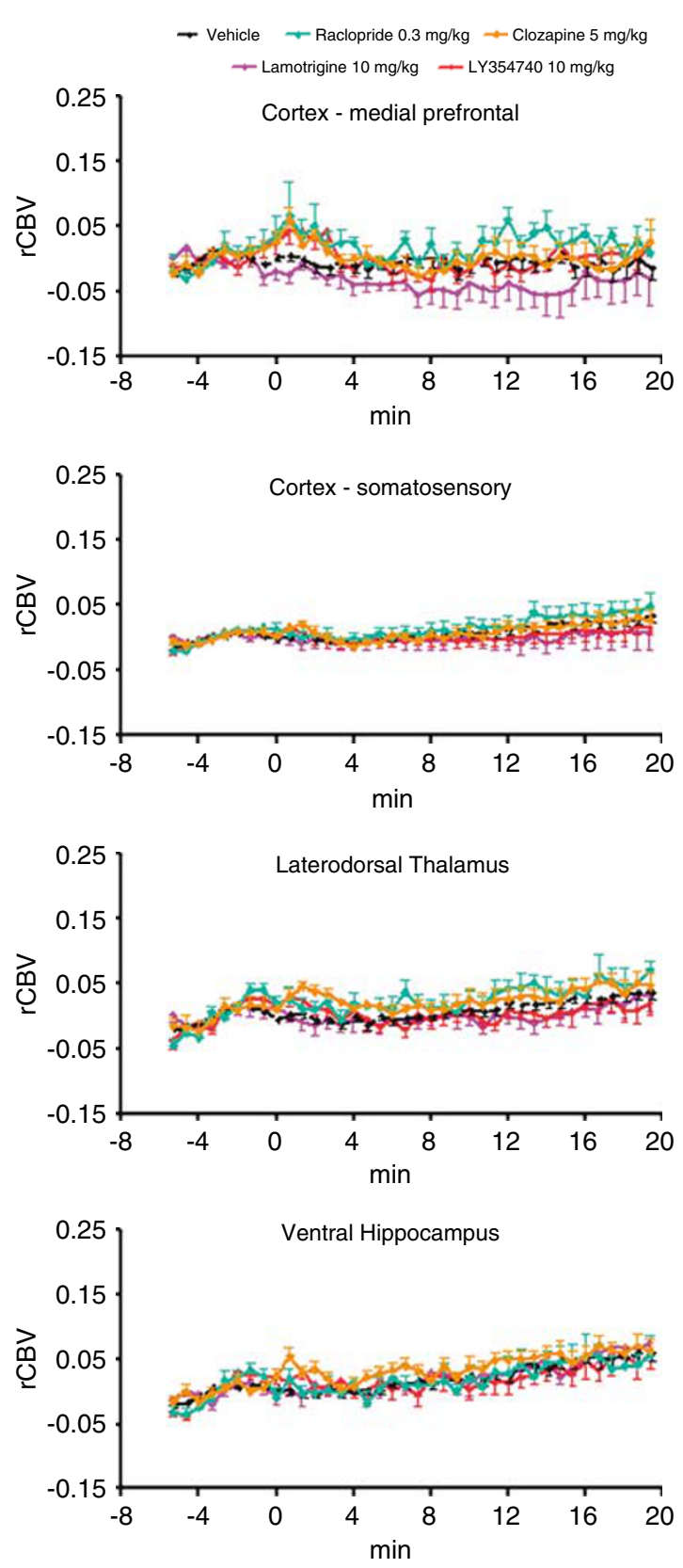

Figure 5 Effect of pretreatment per se on basal rCBV in four representative brain regions. Drugs were administered at time 0 . Data are plotted as mean \pm SEM within each group.

investigated the functional response to PCP in isofluraneanesthetized rats using perfusion imaging. Similar to the present study, they reported increased perfusion in the enthorhinal cortex, nucleus accumbens shell, thalamus, and ventral pallidum; however, they reported decreased perfusion in prefrontal and temporal cortices and dorsal striatum, and no change in the hippocampus. The presence of areas of decreased perfusion in limbic cortical structures is at odds with our results. A possible explanation for this discrepancy is the use of a higher level of anesthetic (1.6 MAC (minimum alveolar concentration) of isoflurane) than that used in the present study (0.8 MAC (minimum alveolar concentration) of halothane). As PCP itself acts as a general anesthetic at sufficiently high doses, and as discussed earlier in relation to appropriate combination of PCP dose and level of anesthesia, the findings by Risterucci might reflect a general suppression of cortical activity resulting from the use of a higher dose of PCP combined with high levels of isoflurane (Gozzi et al, 2007b).

PCP altered rCBV in well-defined neural structures, such as the prefrontal cortex, hippocampus, amygdala, and thalamus, which are known to form a cortico-limbothalamic loop that has been the subject of research into the underlying neuropathological basis of schizophrenia (Large, 2007). While acute administration of PCP is unlikely to mimic comprehensively a complex multifactorial disease like schizophrenia, at some level PCP may, however, modify neural function in these key circuits to induce some symptoms in healthy humans that are remarkably similar to symptoms of psychosis. For instance, functional impairment of limbic cortical areas has been shown to be coupled to the decline in executive functioning that is often experienced by patients with schizophrenia (Kircher and Thienel, 2005). Similarly, dysfunction of the posterior cingulate and retrosplenial cortices has been associated with the development of thought disorder, disturbance of consciousness, and overall cognitive decline (Mitelman et al, 2005). Dysregulation of the amygdala-hippocampus complex has been linked to symptoms of affect, such as the inability to recognize emotional faces (Mancini-Marie et al, 2004; Schneider et al, 1998). Furthermore, aberrant hippocampal activity has been associated with memory impairment, which is observed in patients with schizophrenia (Kircher and Thienel, 2005). Likewise, the identification of focal activation by PCP of areas of the thalamus is in agreement with recent evidence supporting a critical role for this region in the pathophysiology of schizophrenia (Clinton and Meador-Woodruff, 2004). Finally, PCP-induced activation of mesolimbic and nigrostriatal structures is in good agreement with the classical dopamine hypothesis of schizophrenia, where dysregulation of accumbens dopamine transmission is implicated in the onset of positive symptoms. Overall, these observations suggest a degree of overlap between the regions that are affected by PCP, and some of the key brain circuits that may be dysfunctional in schizophrenia. Consequently, the use of PCP combined with functional neuroimaging provides a valuable approach to identifying neuropathological processes that might contribute to the symptoms of schizophrenia. Importantly, the approach is also ideally suited for investigating the site of action of existing and future antipsychotic drugs.

\section{Effect of Antipsychotic Drugs}

Among the atypical antipsychotic agents, clozapine possesses superior efficacy in the treatment of patients with schizophrenia, especially in those refractory to therapy with conventional $\mathrm{D}_{2}$ receptor antagonists (Tandon and Fleischhacker, 2005; Kane et al, 1988). In the present study, pretreatment with clozapine produced a profound suppression of the response to PCP in specific brain structures, such as the cingulate and medial prefrontal cortex, the thalamus, the antero-dorsal hippocampus, and the striatum. Our results are consistent with preclinical work examining the effects of clozapine on NMDAR function. Studies have shown that clozapine, but not the $\mathrm{D}_{2}$ receptor antagonist 
haloperidol, reversed deficits in cognitive and social behavior induced by NMDAR agonists in rodents, primates (Idris $e t$ al, 2005; Gaisler-Salomon and Weiner, 2003; Linn et al, 2003; Qiao et al, 2001), and humans (Malhotra et al, 1997a). Similar findings have been reported using functional readouts such as 2DG uptake (Duncan et al, 1998a, 2000).

The pharmacological profile of clozapine is broad, including affinity for $\mathrm{D}_{1}$ and $\mathrm{D}_{2}$ dopamine receptors, and potent antagonist action at affinity for $5-\mathrm{HT}_{2 \mathrm{~A}}, 5-\mathrm{HT}_{2 \mathrm{C}}$, $5-\mathrm{HT}_{6}, 5-\mathrm{HT}_{7}, \alpha_{1}$ - and $\alpha_{2}$-adenergic, histamine $\mathrm{H}_{1}$, and muscarinic $M_{1}$ receptors (Meltzer, 1996). Classically, $D_{2}$ receptor blockade has been considered to be the key pharmacological mechanism underlying clozapine efficacy. However, in the present study, pretreatment with the selective dopamine $\mathrm{D}_{2}$ antagonist raclopride did not produce significant inhibition of the response to PCP in any of the regions analyzed. Raclopride was given at a subcataleptic dose that is expected to produce $\sim 75 \%$ dopamine $\mathrm{D}_{2}$ receptor occupancy (Wadenberg et al, 2000), a value that is in line with the threshold of occupancy $(65-70 \%)$ required for therapeutic effect in patients with schizophrenia (Farde et al, 1992). The same dose of raclopride has also been shown to be active in tests classically considered to reflect in vivo blockade of DA transmission, such as D-amphetamine-induced hyperlocomotion (Mark et al, 2004; Maurel-Remy et al, 1995). In contrast, the dose of clozapine tested in the present study would be expected to occupy just $40 \%$ of dopamine $\mathrm{D}_{2}$ receptors (Kapur et al, 2003; Mukherjee et al, 2001), a value that is also consistent with the occupancies determined in schizophrenic patients treated with clozapine (eg 16-68\% in Kapur et al, 1999; 20-67\% in Nordstrom et al, 1995). Thus, the lack of inhibitory effect of raclopride at a dose that significantly blocks dopamine $\mathrm{D}_{2}$ neurotransmission argues against a primary role for dopamine $\mathrm{D}_{2}$ receptors in the generation of psychotic symptoms by NMDAR antagonists, and suggests that the efficacy of clozapine in the models is not due to $\mathrm{D}_{2}$ receptor blockade. Consistent with the present observations with raclopride, NMDAR antagonists are reported to increase dopamine release in limbic and frontal cortical brain areas (Adams and Moghaddam, 1998; Hertel et al, 1995), but dopamine $\mathrm{D}_{2}$ receptor antagonists or dopamine depletion was unable to prevent the behavioral effects induced by NMDAR antagonists in rodents (Idris et al, 2005; Linn et al, 2003; Carlsson et al, 1999; Duncan et al, 1998a; Corbett et al, 1995) and humans (Krystal et al, 1999). These findings also underscore a potential limitation in the validity of the NMDAR deficit model as a tool to predict the therapeutic efficacy of antipsychotic agents relying on blockade of $\mathrm{D}_{2}$ dopamine receptors.

Clozapine also has affinity for dopamine $D_{1}$ receptors, although it is still unclear whether the drug acts as an agonist or antagonist (Tauscher et al, 2004). $\mathrm{D}_{1}$ receptor activation by other drugs has also been shown to promote NMDAR function (Flores-Hernandez et al, 2002; Morari et al, 1994). Alternatively, or in addition, clozapine may potentiate NMDAR activation by elevating synaptic levels of glycine through inhibition of type 1 glycine transporters (GlyT-1) (Javitt et al, 2005). Such a mechanism could also be implicated in the focal effect of clozapine in the thalamus, given the high level of Gly-T1 receptor expression in this region, with respect to the cortex and other limbic areas (Zafra et al, 1995). Thus the efficacy of clozapine in the present study might arise through a direct or indirect enhancement of NMDAR function, counteracting the effect of NMDAR block by PCP.

Clozapine has a high affinity for $5-\mathrm{HT}_{2 \mathrm{~A}}$ receptors so it is also possible that these receptors mediate the efficacy of the drug in the present model, perhaps via an indirect modulatory effect on cortical glutamate neurotransmission (Seeman, 2002; Aghajanian and Marek, 1999). This is also consistent with the strong effects observed with lamotrigine and LY354740, which are also thought to act via the inhibition of glutamate transmission. However, direct studies of the effects of clozapine on glutamate release have produced conflicting results, with both increased (Yamamoto and Cooperman, 1994; Daly and Moghaddam, 1993) and decreased (Yang and Wang, 2005) levels of cortical glutamate observed following the administration of clozapine to rats.

The observation from the present study that clozapine produces a stronger effect in the thalamus, compared to the cortex or limbic brain areas, is of particular interest and suggests a regional selectivity that might be key to understanding the functional basis of its pharmacological action. It can be speculated that the superior therapeutic efficacy of clozapine with respect to other antipsychotics (Tandon and Fleischhacker, 2005; Breier et al, 1994; Kane et al, 1988) might be at least partly mediated by a more effective restoration (or preservation) of thalamic function. This hypothesis would be consistent with the recent neuropathological and neuroimaging evidence pointing to structural and metabolic abnormalities in the thalamus giving rise to deficits in sensory processing and some symptoms of psychosis (Sim et al, 2006; Clinton and Meador-Woodruff, 2004). The regional specificity of clozapine might also provide an additional clue as to the contribution of specific receptor systems to its mechanism of action. For example, serotonin $5-\mathrm{HT}_{7}$ receptors are highly expressed in the thalamus, and are known to be inhibited by clozapine (Heidmann et al, 1998). It is, therefore, tempting to speculate that $5-\mathrm{HT}_{7}$ receptors might be implicated in the focal effect of clozapine on the thalamus. Consistent with this hypothesis, a recent study showed that the selective serotonin $5-\mathrm{HT}_{7}$ agonist SB269970A prevented deficits in reversal learning induced by PCP in rats (Neill et al, 2006). It is also noteworthy that recent genetic or post mortem studies have implicated $5-\mathrm{HT}_{7}$ receptors in the pathology underlying schizophrenia (Dean et al, 2006; Ikeda et al, 2006; East et al, 2002).

\section{Effect of LY354740}

LY354740 produced a potent and widespread suppression of the rCBV response to PCP. This compound is a selective metabotropic glutamate (mGlu) 2/3 receptor agonist that can prevent glutamate hyperexcitation by decreasing the evoked release of glutamate from forebrain and limbic glutamatergic synapses (Schoepp and Marek, 2002; Cartmell and Schoepp, 2000). Consistent with this, LY354740 has been shown to inhibit increases in glutamate induced by the depolarizing agent veratridine in the striatum of freely moving rats (Battaglia et al, 1997), and reduce the response to electrically evoked glutamate release in a manner 
consistent with a presynaptic site of action (Capogna, 2004; Kilbride et al, 1998). Agonists of mGluR2/3 such as LY354740 can antagonize the behavioral and neurochemical effects of PCP in rodents (Lorrain et al, 2003; Cartmell et al, 1999; Moghaddam and Adams, 1998) and produce a dosedependent suppression of ketamine-induced impairment of working memory by ketamine in human volunteers (Krystal et al, 2005). Our results show a significant inhibition of the amplitude of the response to PCP in most of the activated regions, an effect that parallels the preclinical and clinical findings mentioned above.

The results with LY354740, a compound that can modulate glutamate release, add to a growing body of evidence that implicates glutamate transmission and an aberrant activity of glutamatergic neurons (eg cortical and hippocampal pyramidal cells) in the behavioral and neurometabolic effects of NMDA antagonists. Electrophysiological and neurotoxicological studies suggest that the cognitive, psychotomimetic, and eventually neurodegenerative actions of NMDA antagonists are dose-dependent manifestations of a general inhibition of GABAergic interneurons, resulting in unregulated activity of principal neurons leading to excessive release of glutamate (Farber, 2003; Greene, 2001). By selectively disinhibiting cortical interneurons, psychotogenic doses of NMDA can produce an increased glutamate transmission via non-NMDA glutamate receptors over major excitatory projections from the cortex to the basal forebrain and the thalamus, thus originating a hyperexcitatory state that is thought to underlie NMDA-induced psychosis. Our findings that LY354740 completely suppressed the response to PCP are in agreement with this theory. It is noteworthy that the response suppression was widespread and affected all the activated regions, suggesting that disruption of glutamate transmission may occur early in the cascade of events leading from NMDAR blockade to psychomimetic reaction.

The observation that LY354740 can produce anxiolytic effects on rodents (Ferris et al, 2001) has led some authors to hypothesize a direct involvement of $m G$ luR2/3 receptors in GABA neurotransmission. However, neurophysiological and neuroanatomical studies do not provide evidence of a direct modulation of GABAergic activity by mGluR2/3 agonists, and preclinical data suggest that the anxiolytic action of LY354740 is probably mediated by an inhibition of glutamate release from excitatory inputs to crucial brain structures, such as the amygdala and hypothalamus (reviewed by Swanson et al, 2005). Moreover, drugs that do directly enhance GABAergic inhibition (eg sodium valproate, diazepam, lorazepam) do not prevent the effects of NMDAR antagonists in either rodents or humans (Large, 2007; Krystal et al, 1998), thus suggesting that GABA-enhancement alone is not sufficient to prevent the psychotomimetic action of NMDA antagonists (Large, 2007). Taken together, these findings point to a modulation of glutamate release as the most plausible mechanism by which LY354740 can inhibit the psychotomimetic effects of PCP.

\section{Effect of Lamotrigine}

Lamotrigine is a broad spectrum anticonvulsant that inhibits voltage-gated sodium channels in a use-dependent manner; the drug has also been shown to reduce neuronal excitability and glutamatergic transmission (Large et al, 2005). Studies in rodents show that acute treatment with lamotrigine can prevent the disruption of behavior induced by NMDA antagonists (Large et al, 2005), and in healthy human volunteers lamotrigine has been shown to attenuate positive, negative, and cognitive effects of ketamine (Anand et al, 2000). In the present study, pretreatment with lamotrigine produced a potent and widespread inhibition of the $\mathrm{rCBV}$ response to PCP in all the activated regions, which is consistent with recent results showing that lamotrigine pretreatment can reduce the BOLD response to ketamine in healthy human volunteers (McKie et al, 2007).

Several studies have shown that PCP, ketamine, and other NMDAR antagonists can induce aberrant glutamatergic neurotransmission by altering the firing of cortical neurons in rats (Jodo et al, 2005; Jackson et al, 2004; Tamminga et al, 2003; Shi and Zhang, 2003). Thus the efficacy of lamotrigine in these models and in the present study supports the hypothesis that the psychotomimetic effects of NMDAR antagonists arise through dysregulation of cortical neural activity and possibly an increase in excitatory transmission. However, since glutamate release is intimately linked to the underlying pattern of neuronal activity, it is not yet clear whether lamotrigine effects are directed at one or the other. Despite this, the efficacy of lamotrigine underscores once more a central role of dysregulation of cortical neuronal activity and glutamate release in the psychotomimetic effect of NMDAR antagonists. The widespread effect of lamotrigine, reducing the PCP-induced $\mathrm{rCBV}$ response in all brain areas, further indicates that the inhibition of activity and/or glutamate transmission lies proximal to the primary effect of NMDAR antagonists.

In conclusion, we investigated the spatio-temporal distribution of changes in $\mathrm{rCBV}$ induced by acute challenge with PCP in the anesthetized rat and examined how these effects are modulated by drugs that differentially modify NMDAR antagonist-induced behaviors. PCP produced increases in rCBV in discrete cortico-limbo-thalamic regions. This effect was strongly suppressed by pretreatment with compounds that can reduce neuronal excitability and modulate glutamatergic transmission such as the sodium channel blocker lamotrigine and the mGluR2/3 agonist LY354740, thus corroborating the pivotal role of cortical glutamatergic neurotransmission in the psychotomimetic action of NMDAR antagonists. Pretreatment with the selective $\mathrm{D}_{2}$ dopamine antagonist raclopride did not significantly affect the response to PCP, a finding that argues against a primary role for dopamine $D_{2}$ receptors in the functional response elicited by NMDAR antagonists. Finally, clozapine produced a region-dependent suppression of PCP response, with moderate but significant inhibition in the cortex, and total response suppression in the thalamus. This regional effect of NMDAR antagonists could be key to elucidating the functional basis of clozapine pharmacological action.

\section{DISCLOSURE/CONFLICT OF INTEREST}

We declare that, except for income received from my primary employer, no financial support or compensation has been received from any individual or corporate entity 
over the past 3 years for research or professional service and there are no personal financial holdings that could be perceived as constituting a potential conflict of interest.

\section{REFERENCES}

Adams B, Moghaddam B (1998). Corticolimbic dopamine neurotransmission is temporally dissociated from the cognitive and locomotor effects of phencyclidine. J Neurosci 18: 5545-5554.

Adler CM, Malhotra AK, Elman I, Goldberg T, Egan M, Pickar D et al (1999). Comparison of ketamine-induced thought disorder in healthy volunteers and thought disorder in schizophrenia. Am J Psychiatry 156: 1646-1649.

Aghajanian GK, Marek GJ (1999). Serotonin, via 5-HT2A receptors, increases EPSCs in layer V pyramidal cells of prefrontal cortex by an asynchronous mode of glutamate release. Brain Res 825: 161-171.

Anand A, Charney DS, Oren DA, Berman RM, Hu XS, Cappiello A et al (2000). Attenuation of the neuropsychiatric effects of ketamine with lamotrigine: support for hyperglutamatergic effects of N-methyl-D-aspartate receptor antagonists. Arch Gen Psychiatry 57: 270-276.

Bakshi VP, Swerdlow NR, Geyer MA (1994). Clozapine antagonizes phencyclidine-induced deficits in sensorimotor gating of the startle response. J Pharmacol Exp Ther 271: 787-794.

Battaglia G, Monn JA, Schoepp DD (1997). In vivo inhibition of veratridine-evoked release of striatal excitatory amino acids by the group II metabotropic glutamate receptor agonist LY354740 in rats. Neurosci Lett 229: 161-164.

Boxerman JL, Hamberg LM, Rosen BR, Weisskoff RM (1995). MR contrast due to intravascular magnetic susceptibility perturbations. Magn Reson Med 34: 555-566.

Breier A, Buchanan RW, Kirkpatrick B, Davis OR, Irish D, Summerfelt A et al (1994). Effects of clozapine on positive and negative symptoms in outpatients with schizophrenia. Am J Psychiatry 151: 20-26.

Brody SA, Geyer MA, Large CH (2003). Lamotrigine prevents ketamine but not amphetamine-induced deficits in prepulse inhibition in mice. Psychopharmacology (Berl) 169: 240-246.

Capogna M (2004). Distinct properties of presynaptic group II and III metabotropic glutamate receptor-mediated inhibition of perforant pathway-CA1 EPSCs. Eur J Neurosci 19: 2847-2858.

Carlsson A, Waters N, Carlsson ML (1999). Neurotransmitter interactions in schizophrenia-therapeutic implications. Biol Psychiatry 46: 1388-1395.

Cartmell J, Monn JA, Schoepp DD (1999). The metabotropic glutamate $2 / 3$ receptor agonists LY354740 and LY379268 selectively attenuate phencyclidine versus d-amphetamine motor behaviors in rats. J Pharmacol Exp Ther 291: 161-170.

Cartmell J, Schoepp DD (2000). Regulation of neurotransmitter release by metabotropic glutamate receptors. J Neurochem 75: 889-907.

Cavazzuti M, Porro CA, Biral GP, Benassi C, Barbieri GC (1987). Ketamine effects on local cerebral blood flow and metabolism in the rat. J Cereb Blood Flow Metab 7: 806-811.

Clinton SM, Meador-Woodruff JH (2004). Thalamic dysfunction in schizophrenia: neurochemical, neuropathological, and in vivo imaging abnormalities. Schizophr Res 69: 237-253.

Corbett R, Camacho F, Woods AT, Kerman LL, Fishkin RJ, Brooks $\mathrm{K}$ et al (1995). Antipsychotic agents antagonize non-competitive $\mathrm{N}$-methyl-D-aspartate antagonist-induced behaviors. Psychopharmacology (Berl) 120: 67-74.

Daly DA, Moghaddam B (1993). Actions of clozapine and haloperidol on the extracellular levels of excitatory amino acids in the prefrontal cortex and striatum of conscious rats. Neurosci Lett 152: 61-64.

Dean B, Pavey G, Thomas D, Scarr E (2006). Cortical serotonin7, $1 \mathrm{D}$ and $1 \mathrm{~F}$ receptors: effects of schizophrenia, suicide and antipsychotic drug treatment. Schizophr Res 88: 265-274.
Duncan GE, Leipzig JN, Mailman RB, Lieberman JA (1998a). Differential effects of clozapine and haloperidol on ketamineinduced brain metabolic activation. Brain Res 812: 65-75.

Duncan GE, Miyamoto S, Leipzig JN, Lieberman JA (1999a). Comparison of brain metabolic activity patterns induced by ketamine, MK-801 and amphetamine in rats: support for NMDA receptor involvement in responses to subanesthetic dose of ketamine. Brain Res 843: 171-183.

Duncan GE, Miyamoto S, Leipzig JN, Lieberman JA (1999b). Comparison of brain metabolic activity patterns induced by ketamine, MK-801 and amphetamine in rats: support for NMDA receptor involvement in responses to subanesthetic dose of ketamine. Brain Res 843: 171-183.

Duncan GE, Miyamoto S, Leipzig JN, Lieberman JA (1999c). Comparison of brain metabolic activity patterns induced by ketamine, MK-801 and amphetamine in rats: support for NMDA receptor involvement in responses to subanesthetic dose of ketamine. Brain Res 843: 171-183.

Duncan GE, Miyamoto S, Leipzig JN, Lieberman JA (1999d). Comparison of brain metabolic activity patterns induced by ketamine, MK-801 and amphetamine in rats: support for NMDA receptor involvement in responses to subanesthetic dose of ketamine. Brain Res 843: 171-183.

Duncan GE, Miyamoto S, Leipzig JN, Lieberman JA (2000). Comparison of the effects of clozapine, risperidone, and olanzapine on ketamine-induced alterations in regional brain metabolism. J Pharmacol Exp Ther 293: 8-14.

Duncan GE, Moy SS, Knapp DJ, Mueller RA, Breese GR (1998b). Metabolic mapping of the rat brain after subanesthetic doses of ketamine: potential relevance to schizophrenia. Brain Res 787: 181-190.

East SZ, Burnet PWJ, Kerwin RW, Harrison PJ (2002). An RT-PCR study of 5-HT6 and 5-HT7 receptor mRNAs in the hippocampal formation and prefrontal cortex in schizophrenia. Schizophr Res 57: $15-26$.

Farber NB (2003). The NMDA receptor hypofunction model of psychosis. Ann NY Acad Sci 1003: 119-130.

Farde L, Nordstrom AL, Wiesel FA, Pauli S, Halldin C, Sedvall G (1992). Positron emission tomographic analysis of central D1 and D2 dopamine receptor occupancy in patients treated with classical neuroleptics and clozapine. Relation to extrapyramidal side effects. Arch Gen Psychiatry 49: 538-544.

Ferris P, Seward E, Dawson GR (2001). Interactions between LY354740, a Group II metabotropic agonist and the GABAAbenzodiazepine receptor complex in the rat elevated plus-maze. J Psychopharmacol 15: 76-82.

Flores-Hernandez J, Cepeda C, Hernandez-Echeagaray E, Calvert CR, Jokel ES, Fienberg AA et al (2002). Dopamine enhancement of NMDA currents in dissociated medium-sized striatal neurons: role of D1 receptors and DARPP-32. J Neurophysiol 88: 3010-3020.

Friston KJ, Jezzard P, Turner R (1994). Analysis of functional MRI time-series. Hum Brain Mapp 1: 153-171.

Gaisler-Salomon I, Weiner I (2003). Systemic administration of MK-801 produces an abnormally persistent latent inhibition which is reversed by clozapine but not haloperidol. Psychopharmacology V166: 333-342.

Gozzi A, Ceolin L, Schwarz AJ, Reese T, Bertani S, Bifone A (2007a). A multimodality investigation of cerebral haemodynamics and autoregulation in phMRI. Magn Reson Imaging 25: 826-833.

Gozzi A, Schwarz AJ, Reese T, Bertani S, Crestan V, Bifone A (2005). Region-specific effects of nicotine on brain activity: a pharmacological MRI study in the drug-naïve rat. Neuropsychopharmacology 31: 1690-1703.

Gozzi A, Schwarz AJ, Reese T, Crestan V, Bifone A (2007b). Drug-anaesthetic interaction in pharmacological MRI: the case of the psychotogenic agent phencyclidine, Book of abstracts: 15 th Annual Meeting of the International Society of Magnetic Resonance in Medicine: P2000. 
Greene R (2001). Circuit analysis of NMDAR hypofunction in the hippocampus, in vitro, and psychosis of schizophrenia. Hippocampus 11: 569-577.

Heidmann DEA, Szot P, Kohen R, Hamblin MW (1998). Function and distribution of three rat 5-hydroxytryptamine7 (5-HT7) receptor isoforms produced by alternative splicing. Neuropharmacology 37: 1621-1632.

Hennig J, Nauerth A, Friedburg H (1986). RARE imaging: a fast imaging method for clinical MR. Magn Reson Med 3: 823-833.

Hertel P, Mathe JM, Nomikos GG, Iurlo M, Mathe AA, Svensson TH (1995). Effects of d-amphetamine and phencyclidine on behavior and extracellular concentrations of neurotensin and dopamine in the ventral striatum and the medial prefrontal cortex of the rat. Behav Brain Res 72: 103-114.

Holcomb HH, Lahti AC, Medoff DR, Cullen T, Tamminga CA (2005). Effects of noncompetitive NMDA receptor blockade on anterior cingulate cerebral blood flow in volunteers with schizophrenia. Neuropsychopharmacology 30: 2275-2282.

Homayoun H, Jackson ME, Moghaddam B (2005). Activation of metabotropic glutamate $2 / 3$ receptors reverses the effects of NMDA receptor hypofunction on prefrontal cortex unit activity in awake rats. J Neurophysiol 93: 1989-2001.

Idris NF, Repeto P, Neill JC, Large CH (2005). Investigation of the effects of lamotrigine and clozapine in improving reversal-learning impairments induced by acute phencyclidine and D-amphetamine in the rat. Psychopharmacology (Berl) 179: 336-348.

Ikeda M, Iwata N, Kitajima T, Suzuki T, Yamanouchi Y, Kinoshita $\mathrm{Y}$ et al (2006). Positive association of the serotonin 5-HT7 receptor gene with schizophrenia in a Japanese population. Neuropsychopharmacology 31: 866-871.

Jackson ME, Homayoun H, Moghaddam B (2004). NMDA receptor hypofunction produces concomitant firing rate potentiation and burst activity reduction in the prefrontal cortex. Proc Natl Acad Sci USA 101: 8467-8472.

Javitt DC, Duncan L, Balla A, Sershen H (2005). Inhibition of system A-mediated glycine transport in cortical synaptosomes by therapeutic concentrations of clozapine: implications for mechanisms of action. Mol Psychiatry 10: 275-287.

Javitt DC, Zukin SR (1991). Recent advances in the phencyclidine model of schizophrenia. Am J Psychiatry 148: 1301-1308.

Jodo E, Suzuki Y, Katayama T, Hoshino KY, Takeuchi S, Niwa SI et al (2005). Activation of medial prefrontal cortex by phencyclidine is mediated via a hippocampo-prefrontal pathway. Cereb Cortex 15: 663-669.

Kane J, Honigfeld G, Singer J, Meltzer H (1988). Clozapine for the treatment-resistant schizophrenic. A double-blind comparison with chlorpromazine. Arch Gen Psychiatry 45: 789-796.

Kapur S, VanderSpek SC, Brownlee BA, Nobrega JN (2003). Antipsychotic dosing in preclinical models is often unrepresentative of the clinical condition: a suggested solution based on in vivo occupancy. J Pharmacol Exp Ther 305: 625-631.

Kapur S, Zipursky RB, Remington G (1999). Clinical and theoretical implications of 5-HT2 and D2 receptor occupancy of clozapine, risperidone, and olanzapine in schizophrenia. Am J Psychiatry 156: 286-293.

Kilbride J, Huang LQ, Rowan MJ, Anwyl R (1998). Presynaptic inhibitory action of the group II metabotropic glutamate receptor agonists, LY354740 and DCG-IV. Eur J Pharmacol 356: 149-157.

Kircher TT, Thienel R (2005). Functional brain imaging of symptoms and cognition in schizophrenia. Prog Brain Res 150: 299-308.

Kohler C, Hall H, Ogren SO, Gawell L (1985). Specific in vitro and in vivo binding of $3 \mathrm{H}$-raclopride a potent substituted benzamide drug with high affinity for dopamine D-2 receptors in the rat brain. Biochem Pharmacol 34: 2251-2259.

Kristiansen LV, Huerta I, Beneyto M, Meador-Woodruff JH (2007). NMDA receptors and schizophrenia. Curr Opin Pharmacol 7: 48-55. Krystal JH, Abi-Saab W, Perry E, D'Souza DC, Liu N, Gueorguieva R et al (2005). Preliminary evidence of attenuation of the disruptive effects of the NMDA glutamate receptor antagonist, ketamine, on working memory by pretreatment with the group II metabotropic glutamate receptor agonist, LY354740, in healthy human subjects. Psychopharmacology (Berl) 179: 303-309.

Krystal JH, D’Souza DC, Karper LP, Bennett A, Abi-Dargham A, Abi-Saab D et al (1999). Interactive effects of subanesthetic ketamine and haloperidol in healthy humans. Psychopharmacology (Berl) 145: 193-204.

Krystal JH, Karper LP, Bennett A, D'Souza DC, Abi-Dargham A, Morrissey $\mathrm{K}$ et al (1998). Interactive effects of subanesthetic ketamine and subhypnotic lorazepam in humans. Psychopharmacology (Berl) 135: 213-229.

Lahti AC, Weiler MA, Tamara Michaelidis BA, Parwani A, Tamminga CA (2001). Effects of ketamine in normal and schizophrenic volunteers. Neuropsychopharmacology 25: 455-467.

Lahti RA, Evans DL, Stratman NC, Figur LM (1993). Dopamine D4 versus $\mathrm{D} 2$ receptor selectivity of dopamine receptor antagonists: possible therapeutic implications. Eur J Pharmacol 236: 483-486.

Langsjo JW, Kaisti KK, Aalto S, Hinkka S, Aantaa R, Oikonen V et al (2003). Effects of subanesthetic doses of ketamine on regional cerebral blood flow, oxygen consumption, and blood volume in humans. Anesthesiology 99: 614-623.

Large CH (2007). Do NMDA receptor antagonist models of schizophrenia predict the clinical efficacy of antipsychotic drugs? J Psychopharmacol 21: 283-301.

Large $\mathrm{CH}$, Webster EL, Goff DC (2005). The potential role of lamotrigine in schizophrenia. Psychopharmacology (Berl) 181: 415-436.

Linn S, Negi S, Gerum V, Javitt C (2003). Reversal of phencyclidine-induced prepulse inhibition deficits by clozapine in monkeys. Psychopharmacology V169: 234-239.

Littlewood CL, Jones N, O'Neil MJ, Mitchell SN, Tricklebank M, Williams MS (2006a). Mapping the central effects of ketamine in the rat using pharmacological MRI. Psychopharmacology V186: 64-81.

Littlewood CL, Diana C, Dixon AL, Dix SL, White CT, O'neill MJ et al (2006b). Using the BOLD MR signal to differentiate the stereoisomers of ketamine in the rat. NeuroImage 32: 1733-1746.

Lorrain DS, Baccei CS, Bristow LJ, Anderson JJ, Varney MA (2003). Effects of ketamine and N-methyl-D-aspartate on glutamate and dopamine release in the rat prefrontal cortex: modulation by a group II selective metabotropic glutamate receptor agonist LY379268. Neuroscience 117: 697-706.

Malhotra AK, Adler CM, Kennison SD, Elman I, Pickar D, Breier A (1997a). Clozapine blunts N-methyl-D-aspartate antagonistinduced psychosis: a study with ketamine. Biol Psychiatry 42: 664-668.

Malhotra AK, Pinals DA, Adler CM, Elman I, Clifton A, Pickar D et al (1997b). Ketamine-induced exacerbation of psychotic symptoms and cognitive impairment in neuroleptic-free schizophrenics. Neuropsychopharmacology 17: 141-150.

Malhotra AK, Pinals DA, Weingartner H, Sirocco K, Missar CD, Pickar D et al (1996). NMDA receptor function and human cognition: the effects of ketamine in healthy volunteers. Neuropsychopharmacology 14: 301-307.

Mancini-Marie A, Stip E, Fahim C, Mensour B, Leroux JM, Beaudoin $G$ et al (2004). Fusiform gyrus and possible impairment of the recognition of emotional expression in schizophrenia subjects with blunted affect: a fMRI preliminary report. Brain Cogn 54: 153-155.

Mandeville JB, Marota JJA, Kosofsky BE, Keltner JR, Weissleder R, Rosen B et al (1998). Dynamic functional imaging of relative cerebral blood volume during rat forepaw stimulation. Magn Reson Med 39: 615-624.

Mark JM, Laetitia S, Alain G, Didier C, Mauricette B (2004). The role of dopamine D 3 compared with D 2 receptors in the control of locomotor activity: a combined behavioural and neurochemical analysis with novel, selective antagonists in rats. Psychopharmacology V174: 341-357. 
Maurel-Remy S, Bervoets K, Millan MJ (1995). Blockade of phencyclidine-induced hyperlocomotion by clozapine and MDL 100907 in rats reflects antagonism of 5-HT2A receptors. Eur J Pharmacol 280: R9-R11.

McKie S, Lees J, Hallak J, Deakin JF, Williams SCR (2007). Pretreatment by lamotrigine attenuates the ketamine-induced BOLD response in healthy volunteers: a phMRI study. Book of abstracts: 15th Annual Meeting of the International Society of Magnetic Resonance in Medicine: $\mathrm{p} 24$.

Meibach RC, Glick SD, Cox R, Maayani S (1979). Localisation of phencyclidine-induced changes in brain energy metabolism. Nature 282: 625-626.

Meltzer HY (1996). Pre-clinical pharmacology of atypical antipsychotic drugs: a selective review. Br J Psychiatry Suppl 29: 23-31.

Messenheimer JA (1995). Lamotrigine. Epilepsia 36(Suppl 2): S87-S94.

Millan M (2005). N-Methyl-d-aspartate receptors as a target for improved antipsychotic agents: novel insights and clinical perspectives. Psychopharmacology 179: 30-53.

Mitelman SA, Shihabuddin L, Brickman AM, Hazlett EA, Buchsbaum MS (2005). Volume of the cingulate and outcome in schizophrenia. Schizophr Res 72: 91-108.

Miyamoto S, Leipzig JN, Lieberman JA, Duncan GE (2000). Effects of ketamine, MK-801, and amphetamine on regional brain 2-deoxyglucose uptake in freely moving mice. Neuropsychopharmacology 22: 400-412.

Moghaddam B, Adams BW (1998). Reversal of phencyclidine effects by a group II metabotropic glutamate receptor agonist in rats. Science 281: 1349-1352.

Morari M, O'Connor WT, Ungerstedt U, Fuxe K (1994). Dopamine D1 and D2 receptor antagonism differentially modulates stimulation of striatal neurotransmitter levels by acid. Eur J Pharmacol 256: 23-30.

Morris BJ, Cochran SM, Pratt JA (2005). PCP: from pharmacology to modelling schizophrenia. Curr Opin Pharmacol 5: 101-106.

Mukherjee J, Christian BT, Narayanan TK, Shi B, Mantil J (2001). Evaluation of dopamine D-2 receptor occupancy by clozapine, risperidone, and haloperidol in vivo in the rodent and nonhuman primate brain using 18F-fallypride. Neuropsychopharmacology 25: 476-488.

Nakki R, Sharp FR, Sagar SM, Honkaniemi J (1996). Effects of phencyclidine on immediate early gene expression in the brain. J Neurosci Res 45: 13-27.

Neill JC, Jones DN, Hagan JJ, Thomas DR (2006). Antagonism at 5-HT7 receptors attenuates a PCP-induced reversal learning deficit in the rat. Schizophr Res 81(Suppl): 233.

Nordstrom AL, Farde L, Nyberg S, Karlsson P, Halldin C, Sedvall G (1995). D1, D2, and 5-HT2 receptor occupancy in relation to clozapine serum concentration: a PET study of schizophrenic patients. Am J Psychiatry 152: 1444-1449.

Paxinos G, Watson C (1998). The Rat Brain in Stereotactic Coordinates. Academic Press: San Diego.

Qiao H, Noda Y, Kamei H, Nagai T, Furukawa H, Miura H et al (2001). Clozapine, but not haloperidol, reverses social behavior deficit in mice during withdrawal from chronic phencyclidine treatment. NeuroReport 12: 11-15.

Risterucci C, Jeanneau K, Schoppenthau S, Bielser T, Kunnecke B, von Kienlin $\mathrm{M}$ et al (2005). Functional magnetic resonance imaging reveals similar brain activity changes in two different animal models of schizophrenia. Psychopharmacology (Berl) 180: 724-734.

Schneider F, Weiss U, Kessler C, Salloum JB, Posse S, Grodd W et al (1998). Differential amygdala activation in schizophrenia during sadness. Schizophr Res 34: 133-142.

Schoepp DD, Marek GJ (2002). Preclinical pharmacology of mGlu2/3 receptor agonists: novel agents for schizophrenia? Curr Drug Targets CNS Neurol Disord 1: 215-225.

Schotte A, Bonaventure P, Janssen PF, Leysen JE (1995). In vitro receptor binding and in vivo receptor occupancy in rat and guinea pig brain: risperidone compared with antipsychotics hitherto used. Jpn J Pharmacol 69: 399-412.

Schotte A, Janssen P, Gommeren W, Luyten W, Gompel P, Lesage A et al (1996). Risperidone compared with new and reference antipsychotic drugs: in vitro and in vivo receptor binding. Psychopharmacology 124: 57-73.

Schotte A, Janssen PF, Megens AA, Leysen JE (1993). Occupancy of central neurotransmitter receptors by risperidone, clozapine and haloperidol, measured ex vivo by quantitative autoradiography. Brain Res 631: 191-202.

Schwarz AJ, Danckaert A, Reese T, Gozzi A, Paxinos G, Watson C et al (2006a). A stereotaxic MRI template set for the rat brain with tissue class distribution maps and co-registered anatomical atlas: application to pharmacological MRI. NeuroImage 32: 538-550.

Schwarz AJ, Reese T, Gozzi A, Bifone A (2003). Functional MRI using intravascular contrast agents: detrending of the relative cerebrovascular (rCBV) time course. Magn Reson Imaging 21: 1191-1200.

Schwarz AJ, Whitcher B, Gozzi A, Reese T, Bifone A (2006b). Studylevel wavelet cluster analysis and data-driven signal models in pharmacological MRI. J Neurosci Methods 159: 346-360.

Seeman P (2002). Atypical antipsychotics: mechanism of action. Can J Psychiatry 47: 27-38.

Shi WX, Zhang XX (2003). Dendritic glutamate-induced bursting in the prefrontal cortex: further characterization and effects of phencyclidine. J Pharmacol Exp Ther 305: 680-687.

Sim K, Cullen T, Ongur D, Heckers S (2006). Testing models of thalamic dysfunction in schizophrenia using neuroimaging. J Neural Transm V113: 907-928.

Soyka M, Koch W, Moller HJ, Ruther T, Tatsch K (2005). Hypermetabolic pattern in frontal cortex and other brain regions in unmedicated schizophrenia patients. Results from a FDG-PET study. Eur Arch Psychiatry Clin Neurosci 255: 308-312.

Swanson CJ, Bures M, Johnson MP, Linden AM, Monn JA, Schoepp DD (2005). Metabotropic glutamate receptors as novel targets for anxiety and stress disorders. Nat Rev Drug Discov 4: 131-144.

Tamminga CA, Lahti AC, Medoff DR, Gao XM, Holcomb HH (2003). Evaluating glutamatergic transmission in schizophrenia. Ann NY Acad Sci 1003: 113-118.

Tandon R, Fleischhacker W (2005). Comparative efficacy of antipsychotics in the treatment of schizophrenia: a critical assessment. Schizophr Res 79: 145-155.

Tauscher J, Hussain T, Agid O, Verhoeff NP, Wilson AA, Houle S et al (2004). Equivalent occupancy of dopamine D1 and D2 receptors with clozapine: differentiation from other atypical antipsychotics. Am J Psychiatry 161: 1620-1625.

Wadenberg ML, Kapur S, Soliman A, Jones C, Vaccarino F (2000). Dopamine D2 receptor occupancy predicts catalepsy and the suppression of conditioned avoidance response behavior in rats. Psychopharmacology (Berl) 150: 422-429.

Weissman AD, Dam M, London ED (1987). Alterations in local cerebral glucose utilization induced by phencyclidine. Brain Res 435: 29-40.

Whitcher B, Schwarz AJ, Barjat H, Smart SC, Grundy RI, James MF (2005). Wavelet-based cluster analysis: data-driven grouping of voxel time courses with application to perfusion-weighted and pharmacological MRI of the rat brain. NeuroImage 24: 281-295.

Worsley KJ, Evans AC, Marrett S, Neelin P (1992). A threedimensional statistical analysis for CBF activation studies in human brain. J Cereb Blood Flow Metab 12: 900-918.

Yamamoto BK, Cooperman MA (1994). Differential effects of chronic antipsychotic drug treatment on extracellular glutamate and dopamine concentrations. J Neurosci 14: 4159-4166.

Yang TT, Wang SJ (2005). Effects of haloperidol and clozapine on glutamate release from nerve terminals isolated from rat prefrontal cortex. Synapse 56: 12-20.

Zafra F, Aragon C, Olivares L, Danbolt NC, Gimenez C, StormMathisen J (1995). Glycine transporters are differentially expressed among CNS cells. J Neurosci 15: 3952-3969. 